\title{
As exportações por meio de agentes de venda pela ótica de empresas de médio porte localizadas em Caxias do Sul
}

\section{Patrick Piamolini da Rosa} pprosa1@ucs.br

de Caxias do Sul (UCS), Caxias do Sul, Rio Grande do Sul, Brasil

Guilherme Bergmann Borges Vieira

gbbvieir@ucs.br

Universidade de Caxias do Sul (UCS) Caxias do Sul, Rio Grande do Sul, Brasil

Rogério da Silva França Jr. rsfranj@ucs.br

Universidade de Caxias do Sul (UCS), Caxias do Sul, Rio Grande do Sul, Brasil

\author{
RESUMO
}

A presente pesquisa investigou os principais pontos positivos e negativos da utilização de agentes internacionais de vendas pela ótica de gestores de empresas exportadoras de médio porte de Caxias do Sul. Para tanto, foi desenvolvida uma pesquisa qualitativa exploratória, sendo entrevistados seis gestores mediante a utilização de um roteiro de perguntas semiestruturado. Os resultados das entrevistas foram submetidos à análise de conteúdo, identificando-se que a gestão comercial dos agentes pode ser efetuada de diversas maneiras, através de metas, indicadores de desempenho, relacionamento interpessoal, contratos e rotinas comerciais, e que o sucesso comercial está associado à atuação do gerente de vendas. Com pontos positivos da utilização de agentes internacionais de venda foram identificados o baixo investimento por parte das empresas exportadoras e a velocidade de penetração em novos mercados. Por outro lado, como pontos negativos, podem-se mencionar a eventual perda de controle e o distanciamento aos clientes, dependendo da forma como é conduzido o relacionamento com os agentes.
\end{abstract}

PALAVRAS-CHAVE: Gestão de vendas. Exportação. Agente Internacional de Vendas. 


\section{INTRODUÇÃO}

Esta pesquisa tem como tema principal a gestão comercial por meio de agentes de vendas no contexto do comércio internacional das empresas da Serra Gaúcha. Esse canal de vendas é utilizado com frequência, devido aos benefícios oferecidos, tais como: baixo custo e custo vinculado ao resultado; rápida penetração em grandes áreas de atuação; e conhecimento do mercado local por parte dos agentes.

As vendas têm um papel fundamental em todas as organizações que possuem produtos ou serviços a serem ofertados, pois geram receitas para as mesmas. Por mais que uma empresa não tenha fins lucrativos, a busca por resultados é essencial para sua sobrevivência, mesmo que esse resultado volte a ser investido na organização.

Com o passar dos anos, o ato da venda evoluiu, deixando de ser apenas uma operação dentro do processo das empresas e se tornando o cultivo de um relacionamento. Quando as vendas ocorrem no âmbito internacional, é necessário considerar variáveis diferentes das variáveis do mercado doméstico, sejam estas legais, econômicas ou culturais. Kotabe e Helsen (2000) afirmam que é fundamental ter conhecimento das estratégias internacionais e das condições interculturais para poder diferenciar a administração de vendas internacional da administração de vendas do mercado interno.

O sucesso ou insucesso de uma estratégia comercial passa diretamente pela escolha correta do canal de vendas. De acordo com Roccato (2008), a atuação nas vendas através de canais intermediários é um caminho eficiente para a ampliação da penetração no mercado-alvo. Esse é um dos motivadores para que as empresas optem pela utilização de agentes de vendas no mercado internacional. Um dos benefícios mais relevantes é a relação custo/benefício para a empresa contratante, pois o agente de vendas representa um custo variável, vinculado ao resultado de seu trabalho, evitando vínculo empregatício. Outro benefício encontrado nessa modalidade é que a empresa contratada conhece o mercado local e, portanto, negociará com clientes confiáveis (MINERVINI, 2001). Além disso, estará atenta à entrada de novos clientes e/ou concorrentes na sua região.

A relação entre a empresa contratante e o agente de vendas precisa ser construída com base em relacionamento de confiança e profissionalismo, e a empresa deve fazer uso de ferramentas de controle de resultados para medir o desempenho do agente, cobrando resultados de vendas planejados anteriormente. Diante desse cenário, o presente estudo teve como objetivo analisar a gestão de vendas internacionais por meio do canal do agente de vendas pela ótica das empresas de médio porte da Serra Gaúcha. Com esse intuito, buscou-se: i) analisar características da gestão de vendas internacionais por meio de agentes de vendas; ii) identificar as vantagens e desvantagens da utilização de agentes de vendas nas empresas pesquisadas; e iii) identificar nas empresas estudadas pontos de melhorias, listando ações que poderiam ser implementadas para ganho de resultado.

Diferenciando-se de vendedores contratados, ou representantes do mercado interno, agentes de vendas que atuam no mercado externo necessitam de uma gestão diferenciada para a otimização de seu trabalho. A gestão deve ser 
próxima, de modo a criar um vínculo entre a empresa e o agente, fazendo com que este último venha a desempenhar seu papel comercial com excelência, atingindo as metas de vendas e de penetração nos mercados-alvo. Esta pesquisa pode servir como base para gestores que buscam a melhoria na internacionalização de suas empresas, disponibilizando informações e listando procedimentos e ferramentas a serem usadas no desenvolvimento de um planejamento de exportação através de agentes de venda.

\section{REFERENCIAL TEÓRICO}

Nesta seção é apresentado o referencial teórico que deu sustentação à presente pesquisa. Inicialmente, é apresentada a definição e algumas características inerentes à gestão de vendas internacionais. A seguir, são apresentadas as características da gestão de vendas por meio de agentes internacionais de vendas, sendo descritas as vantagens e desvantagens de sua utilização; as principais características de sua função; o processo de seleção e contratação desse tipo de profissional; os procedimentos relativos à elaboração da previsão e ao estabelecimento das metas de vendas; e os principais fatores relacionados à avaliação de desempenho dos agentes.

\section{GESTÃO DE VENDAS INTERNACIONAIS}

Tradicionalmente, a gestão de vendas acontece através do profissional responsável por gerenciar todos os fatores que envolvem a busca e a concretização de transações comerciais entre duas partes, considerando todos os processos e resultados envolvidos nessa transação. De acordo com Geersbro (2013), a gestão de vendas inclui diversos fatores. Dentre eles, os principais são: i) o gerenciamento de clientes; ii) o gerenciamento do processo de venda; e iii) o gerenciamento da força de vendas.

O gerenciamento de vendas também pode ser definido como a maneira com que os gerentes de vendas monitoram, direcionam, avaliam e recompensam a força de vendas, de acordo com o seu desempenho e suas responsabilidades (BALDAUF; CRAVENS; GRANT, 2002). As práticas do gestor de vendas têm um papel fundamental no desempenho, na motivação e na satisfação do profissional de vendas (KATSIKEA; MORGAN, 2003), influenciando diretamente os resultados comerciais obtidos pela empresa. $O$ gerente de vendas deve estar engajado nas tarefas tradicionais de planejamento, implantação e controle das atividades comerciais, tendo como principal responsabilidade garantir que as ações da força de vendas possam deixar os clientes satisfeitos, oportunizando a continuidade da parceria comercial entre empresa e cliente (HONEYCUTT; FORD; SIMINTIRAS, 2003).

\section{AGENTE DE VENDAS}

Com o passar dos anos, independentemente da evolução tecnológica e de logística, a figura do vendedor continua sendo importante para o desenvolvimento do comércio mundial. As relações humanas são fator crucial 
para o desenvolvimento econômico, e o vendedor é considerado o profissional com maior habilidade de relacionamento, capaz de criar network com objetivos claros de resultado. Esse profissional é quem se dedica a conquistar novos clientes, criando relacionamentos duradouros e de ganho mútuo entre a empresa fornecedora e a empresa adquirente do produto ou serviço oferecido. É o elo que une a necessidade de um produto ou serviço à produção de uma indústria ou empresa.

De acordo com Minervini (2001), o agente de vendas no mercado internacional realiza um trabalho semelhante ao do representante comercial no mercado nacional, podendo ser considerado uma pessoa física ou jurídica que, por meio de acordo ou contrato, vende e representa a empresa pela qual foi contratado, na maioria dos casos sendo remunerado com uma comissão sobre o valor das vendas. Esse conceito é semelhante ao utilizado por Garcia Jr. (2001 p.14), que define o agenciamento como "um ato de representação, realizado pelo agente, para divulgar e eventualmente (se autorizado) concluir negócios em nome de um terceiro (empresário/empresa) que é quem, juridicamente, produz a atividade econômica". Outra definição dada pelo mesmo autor deixa mais claro até onde vão as responsabilidades e a relação entre o agente e o contratante:

Por contrato de agência entende-se o contrato em que uma pessoa física ou jurídica, denominada agente, obriga-se frente a outra, em virtude de uma remuneração, a promover (e concluir, se autorizada) atos ou operações de comércio por conta e em nome alheios, como intermediário independente, sem assumir, salvo pacto contrário, o risco e êxito de tais operações. A atividade do agente baseia-se em uma óbvia relação de confiança entre ele e seu representado (GARCIA JR., 2001, p.13).

A atividade prioritária do agente de vendas é promover e comercializar os produtos da empresa a qual está representando, recebendo um percentual sobre o valor das exportações que foram efetivadas e cujo o pagamento já tenha sido efetuado (CASTRO, 2003).

A atuação do agente de vendas é considerada por Cavusgil, Knight e Riesenberger (2010) uma venda direta, na qual o agente é um intermediário que atua como uma extensão do exportador, negociando em nome da empresa. 0 agente de vendas não pode ser limitado apenas às funções de vendedor, "tirando pedidos" e atendendo demandas de clientes. Deve ser considerado um parceiro na gestão de vendas do mercado-alvo, realizando diversas funções cruciais para o sucesso comercial da empresa.

De acordo com Castro (2003), o agente de vendas deve ter como obrigação as seguintes funções: i) fornecimento regular de relatórios sobre o mercado em que está inserido, tendências futuras, potencialidades, oportunidades de negócios, etc.; ii) fornecimento periódico de dados sobre as atividades desenvolvidas pelos principais concorrentes, tais como preço, campanhas promocionais, produtos, etc.; iii) acompanhamento da evolução do produto no mercado, informando possíveis tendências como preço, design, cores, tamanhos, tecnologias, etc.; e iv) prestação de informações com relação a possíveis mudanças de legislação local que possa dificultar ou facilitar as atividades comerciais.

Existem algumas condições de mercado que favorecem o uso do agente de vendas, tornando-o mais eficiente. Para Dalrymple, Cron e Decarlo (2004), esses 
fatores são: i) mercado fragmentado e clientes difíceis de serem entendidos ou localizados; ii) compra descentralizada; iii) necessidade de conhecimento local do mercado; iv) oferta de uma pequena quantidade de produtos por parte da empresa; v) potencial para agentes que tenham conhecimento de marketing no mercado; vi) empresa pouco conhecida no mercado; vii) produtos sem necessidade de elevado conhecimento técnico; viii) ciclo de vendas curto e pedidos pequenos; ix) pouca necessidade de um controle preciso da força de vendas; e x) pouca necessidade de informações detalhadas dos clientes.

\section{Vantagens e desvantagens da utilização do agente de vendas}

Em virtude do aumento da capacidade de produção ou da estratégia de crescimento em vendas, comumente as empresas buscam atuar comercialmente fora dos seus limites anteriores de alcance físico. Isso acarreta a necessidade de contratação de força de vendas e de estruturação física, o que gera custo elevado e dificuldade de controle por parte do empregador. Por esse motivo, é comum empresas procurarem agentes para a intermediação do contato com o cliente final. De acordo com Bittar (2005), o agente tem papel fundamental na conquista de novos mercados, pois os fabricantes não precisam instituir filiais, sucursais ou agências próprias para atender a um mercado determinado.

Como dito anteriormente, a venda através do agente é considerada direta, isto é, sem a atuação de intermediários no país de origem, como por exemplo trading companies. Por esse motivo, Cavusgil, Knight e Riesenberger (2010) consideram o modelo de venda através de agentes vantajoso na exportação, visto que concede ao exportador maior controle sobre o processo da venda, permitindo um relacionamento mais próximo com o cliente e criando potencial para maiores lucros.

Agentes de vendas têm facilidade de inserção em determinados mercadosalvo. Geralmente, eles representam diversas empresas que possuem produtos complementares, desenvolvendo vendas para clientes similares e conhecidos (DALRYMPLE; CRON; DECARLO, 2004).

Existem diversas vantagens em utilizar o canal do agente de vendas para atuação no comércio internacional. Para Minervini (2008), a principal vantagem está em uma menor necessidade de investimentos financeiros e gerenciais durante o desbravamento do mercado-alvo. Além dessa vantagem, Minervini (2008) lista os seguintes aspectos a serem considerados: o agente conhece o mercado-alvo; é conhecido neste mercado; é motivado à venda, pois esta é sua fonte de renda; e o exportador tem contato direto com os clientes finais e controla os preços praticados.

Pelo fato de o agente de vendas não fazer parte da organização, existem algumas desvantagens em sua utilização na exportação, as quais devem ser consideradas no início do trabalho para evitar problemas subsequentes. De acordo com Minervini (2008), os riscos a serem considerados são: baixo controle sobre o profissional, o que, dependendo das atitudes do agente, pode gerar um risco à imagem da empresa e sua credibilidade junto aos clientes; risco de o agente efetuar vendas para clientes que não irão honrar suas dívidas; caso o agente trabalhe com mais de uma empresa, ele provavelmente irá optar pela que Ihe for mais rentável, deixando as demais de lado; baixo controle do mercado em 
que o agente está inserido, pois todas as informações vêm diretamente do agente; e possibilidade de incompatibilidade entre o agente e a empresa contratante em virtude de políticas de exportação - pedido mínimo, prazos de pagamento e prazos de entrega e preços de venda.

Em relação aos preços de venda, embora maiores preços possam gerar também maiores comissões, os agentes de venda podem praticar preços inferiores aos desejados pelas empresas representadas, com o objetivo de facilitar o processo de venda e garantir o recebimento de sua comissão (LAZEAR, 2015). Isso revela uma questão que tem recebido a atenção tanto do meio acadêmico quanto do empresarial (DAl; CHAO, 2016): a definição dos preços de venda deve ser centralizada na empresa ou descentralizada aos agentes? Segundo os autores, há estudos prévios na literatura defendendo ambas as estratégias. Um dos aspectos que favorece a descentralização é o maior conhecimento do mercado por parte do agente. Por outro lado, a centralização é sugerida em função do potencial conflito de interesse que pode ocorrer na fixação de preços por parte dos agentes. Um aspecto que influencia as duas estratégias é a assimetria de informação entre a empresa e o agente. Essa questão da assimetria de informações é relevante não somente na relação entre empresa exportadora e agente, mas na relação entre diferentes atores no contexto da coordenação da cadeia de suprimentos (Pezeshki et al., 2013)

Para Dalrymple, Cron e Decarlo (2004), o principal aspecto negativo da venda através de agentes é o baixo controle sobre a atuação dos mesmos, uma vez que não se tratam de funcionários da empresa. Isso ocasiona uma disputa pelo seu tempo entre as empresas que ele representa, fazendo com que o relacionamento do gerente com o agente seja crucial para o resultado comercial do mesmo.

\section{CARACTERÍSTICAS DA GESTÃO DE VENDAS POR MEIO DO AGENTE DE VENDAS}

Nesta seção são aprofundados temas relacionados à gestão de vendas por meio do agente de vendas, considerando as funções desempenhadas pelo mesmo e suas responsabilidades. São também abordados fatores como seleção, contratação e avaliação do agente de vendas.

\section{Função do gerente de vendas na gestão do agente de vendas}

Uma figura fundamental na gestão de vendas por meio de agentes de vendas é a do gerente de vendas, também conhecido como gerente comercial. Quando a empresa efetua suas vendas através de agentes, os mesmos são o principal link entre a empresa e o cliente, e o gerente comercial figura como o principal link entre empresa e agente de vendas (MCNEILLY; LAWSON, 1999). Os gerentes de vendas não se limitam a questões apenas operacionais de vendas, também são uma conexão fundamental entre a visão e os valores da alta administração de uma empresa e da força de vendas. Além disso, as práticas adotadas pelo gerente de vendas estão diretamente ligadas ao desempenho e eficácia de sua força de vendas, seja através de agentes ou de outros canais de vendas (MURPHY; LI, 2012). É possível afirmar que os agentes que possuem relações próximas com seus supervisores acabam por receber mais atenção e encorajamento, podendo 
contar com um maior auxílio para atingir as metas propostas pela empresa (MURPHY; LI, 2012).

\section{Seleção e contratação do agente de vendas}

A seleção do agente de vendas para atuação no mercado-alvo é ponto crucial na tomada de decisão da empresa. Lopez e Gama (2005) afirmam que, para que a parceria com o agente de vendas seja eficiente, é fundamental que a agência venha a ser parte integrante da representada. Além disso, é ideal que o contrato seja efetuado apenas após uma visita da empresa ao mercado-alvo e que o representante também conheça a empresa com a qual está iniciando o trabalho e suas políticas comerciais (LOPEZ; GAMA, 2005).

São diversos os fatores que devem ser levados em consideração no momento de selecionar um agente de vendas. Um dos fatores mais relevantes é a compatibilidade da linha de produtos. Um bom agente de vendas representa empresas com produtos que não competem entre si, mas se complementam, com similaridades na qualidade, preço e reputação (DALRYMPLE; CRON; DECARLO, 2004).

Alguns fatores relevantes no perfil do agente de vendas para bem representar uma empresa no exterior são, de acordo com Castro (2011): i) competência comercial e reputação moral; ii) conhecimento técnico do produto e experiência no segmento de mercado; iii) conhecimento dos principais clientes potenciais da região; iv) conhecimento da legislação de comércio exterior do país importador; e v) estrutura física e de pessoas suficiente para atender às necessidades da empresa exportadora. De acordo com Murta (2013), o exportador, antes de firmar contrato com o agente de vendas, deve fazer uma análise minuciosa do profissional em questão, avaliando sua idoneidade profissional, outras representações em que ele já trabalha, suas relações comerciais e seu dinamismo na hora de ofertar os produtos por ele representados.

O processo seletivo do agente de vendas, além de assegurar o sucesso do planejamento comercial da empresa, também evita possíveis problemas. Para Castro (2011), conhecer o perfil do agente de exportação é importante para evitar um agente mal escolhido, inexperiente ou incompetente, que futuramente pode se tornar um obstáculo para a própria empresa, impedindo a exportação para o mercado até o final da vigência do contrato de representação.

Pelo fato de o agente de vendas poder ser uma pessoa física, é inevitável avaliar as características pessoais do mesmo. Para Vieira (2002, p. 56), é importante considerar aspectos como "aparência, desembaraço, fluência verbal, habilidades negociais e de vendas, persuasão, idoneidade, trânsito entre o empresariado, rede de contatos, experiência prévia nesse tipo de serviço, referências bancárias e comerciais".

No comércio internacional, diferentemente do mercado interno, as distâncias e diferenças culturais dificultam a obtenção de contatos sobre possíveis agentes de vendas. Entretanto, existem fontes que podem ser consideradas na busca de candidatos. Para Minervini (2008), as melhores fontes para prospectar agentes são organismos oficiais, sites, associações de fabricantes de produtos similares, exportadores de produtos complementares aos da 
empresa, câmaras de comércio bilaterais, feiras, rodadas de negócios, missões empresariais e diretórios especializados de importadores.

\section{Previsão de vendas e meta de vendas}

De acordo com Soares (2004), é fundamental para a empresa realizar um diagnóstico detalhado do mercado. As informações obtidas a partir do diagnóstico são importantes na hora de desenvolver metas de vendas para os agentes comerciais, destinar áreas de atuação e prever crescimentos futuros de venda e faturamento.

Além de indicadores baseados em resultados mensuráveis, existem ferramentas de avaliação comportamental. Um monitoramento híbrido consiste na avaliação constante por parte do gerente de vendas também de aspectos comportamentais do agente (MURPHY; LI, 2012).

No momento em que uma empresa faz seu planejamento estratégico e nele constam metas de crescimento ou abertura de novos mercados, é necessário considerar previsões de venda e faturamento. A precisão da previsão de vendas pode influenciar diretamente no resultado financeiro da empresa, estipulando orçamentos de investimento para crescimento ou investimento em novos produtos.

De acordo com Stanton e Spiro (2000), pode-se dividir em três os métodos utilizados para prever vendas de um produto ou para um mercado alvo: i) método de pesquisa, no qual a empresa entra em contato com executivos, vendedores e clientes para buscar uma previsão de vendas em um período e mercado determinado; ii) métodos matemáticos, que se dividem em modelo de média móvel, ajustamento exponencial e análise de regressão, baseando-se no histórico de vendas para estipular uma previsão futura - levam em consideração a sazonalidade que um segmento de mercado pode apresentar, porém, não se aplicam à abertura de novos mercados; e iii) métodos operacionais, que efetuam a previsão a partir de uma necessidade ou capacidade interna da empresa, isto é, calculando o potencial máximo de produção ou a venda mínima para pagar as necessidades financeiras - como são utilizados por uma questão de objetivos internos, às vezes podem ser falhos por desconsiderarem o tamanho do mercado e a situação macroeconômica da região.

Após analisar o mercado-alvo, estudar suas possibilidades e considerar o crescimento necessário para a saúde financeira da empresa, devem-se estipular metas e objetivos para o agente de vendas do comércio internacional. Esse processo é fundamental, pois o agente de vendas não está diariamente em contato com a empresa e os seus resultados serão avaliados de acordo com as metas previstas e os objetivos alcançados.

A empresa deve estipular objetivos específicos de vendas para o agente, levando em consideração o período de atuação do agente no mercado, sua carteira atual de clientes e o período necessário para a abertura de novos clientes. A meta é fundamental para a avaliação do desempenho do agente de vendas. 


\section{Avaliação de desempenho}

Não é uma tarefa simples avaliar a atuação de um agente de vendas no comércio internacional, pois, diferentemente de vendedores contratados, o agente não tem vínculo empregatício com a empresa e está distante geograficamente de onde se encontra sua contratante. Ao avaliar um vendedor, é necessário considerar dois grupos de fatores. O primeiro diz respeito aos fatores mensuráveis ou aos números obtidos pelo agente, tais como vendas, crescimento de vendas, vendas/potencial, vendas/metas, novos clientes, margem de contribuição média, entre outros. Esses fatores mostram-se eficientes na melhora do vendedor quando o mesmo tem consciência do que é esperado do seu trabalho, fazendo com que venha a modificar sua estratégia para atingir os objetivos traçados. O segundo grupo de fatores são os comportamentais, relacionados às atitudes do vendedor, tais como ligações com a gerência, relatórios de trabalho, reuniões, viagens efetuadas, reclamações efetuadas, entre outros. Esses fatores são importantes para um controle próximo do trabalho do agente, fazendo com que se tenha controle e se possa melhorar o relacionamento do mesmo com os seus clientes e com a empresa representada. Esses fatores podem ainda ser subdivididos em fatores mais perceptíveis, tais como habilidades de comunicação, conhecimento de produto, atitude, habilidade de venda, agressividade e passividade, aparência e maneiras, trabalho em equipe, entusiasmo, motivação, habilidade de planejamento, conhecimento de precificação, criatividade, entre outros (DALRYMPLE; CRON; DECARLO, 2004).

É importante que o contratante tenha conhecimento de que as metas, objetivos e avaliação dos agentes servem para uso estratégico da empresa. Porém, legalmente, o agente não é devedor de resultado, pois não é possível garantir que o cliente venha a comprar o produto ofertado. Contratualmente, o agente é obrigado a desenvolver sua atividade com diligência e o resultado é uma consequência do trabalho realizado (GARCIA JR., 2001).

\section{MÉTODO}

Para a resolução do problema em estudo, foi escolhida a pesquisa de caráter exploratório. Os estudos de base exploratória tendem a serem realizados de maneira informal, através de conversas com pessoas especializadas no tema em análise (SAMARA; BARROS, 2002). Malhotra (2005) conceitua que o método exploratório tem por objetivo o esclarecimento e a compreensão da situação em análise, com a finalidade de construir conhecimento sobre 0 assunto previamente definido.

Dentre os tipos de pesquisa exploratória, esta pesquisa fez uso de entrevistas individuais em profundidade com especialistas no tema, isto é, gestores que trabalham com agentes de vendas na exportação. De acordo com Malhotra (2005), a pesquisa individual com especialistas pode revelar informações valiosas, mesmo em cenários com ausência de informações disponíveis no mercado.

\section{PROCEDIMENTOS DE COLETA DE DADOS}


Nesta pesquisa foram entrevistados gestores de exportação da cidade de Caxias do Sul com domínio dos processos comerciais e operacionais dessa área e que atuam no comércio internacional através de agentes de vendas. O critério da escolha dos entrevistados foi a proximidade do profissional com as rotinas de exportação, considerando-se como critério de seleção um contato mínimo de uma vez por mês com os agentes de vendas no comércio exterior.

A amostragem foi escolhida por conveniência e julgamento, e os especialistas foram selecionados por se enquadrar nos critérios previamente definidos. O número de profissionais escolhidos se deu de acordo com a saturação dos resultados das entrevistas, isto é, as entrevistas continuaram até que todos os temas propostos tivessem sido abordados de maneira profunda e evidenciassem a repetição de percepções por parte dos entrevistados.

No presente estudo, foi utilizado um roteiro de questões semiestruturadas. Esse instrumento teve como objetivo trazer à tona questões implícitas à realidade cotidiana, buscando aprofundar o tema e entender os processos e cenários em que se encontram os gestores.

\section{PROCEDIMENTOS DE ANÁLISE DE DADOS}

As entrevistas realizadas foram gravadas e submetidas a análise de conteúdo. Para Bardin (2000), a análise de conteúdo compreende diversas técnicas para construir compreensão através da análise da comunicação entre as pessoas. A autora ressalta que esse método é empírico, variando de acordo com o tipo de fala e de interpretação desejada.

A análise de conteúdo deve ser dividida em três fases, de acordo com a cronologia dos fatos (BARDIN, 2000): i) pré-análise - esta primeira fase tem como principal objetivo organizar as ideias e estruturá-las de forma a operacionalizar a análise propriamente dita; esses primeiros procedimentos buscam escolher os documentos que serão analisados, desenvolver hipóteses e fundamentar os objetivos que servirão de base para os indicadores finais; ii) exploração do material - os procedimentos desta fase estão diretamente ligados aos resultados obtidos na fase de pré-análise, sendo apenas o momento em que as regras de codificação ou enumeração são operacionalizadas de forma manual ou computadorizada; e iii) tratamento dos resultados obtidos e interpretação - esta é a fase em que o pesquisador deve validar os resultados obtidos, estabelecendo padrões de resultados através de ferramentas como quadros, figuras ou modelos.

Dentre os diversos tipos de análises existentes, esta pesquisa fez uso do método de categorização (BARDIN, 2000). A categorização pode ser feita mediante diversos critérios. Neste caso, foi utilizado o critério lexical, que classifica palavras de acordo com seu sentido, agrupando palavras com sentidos semelhantes (BARDIN, 2000).

\section{DESCRIÇÃO E ANÁLISE DAS ENTREVISTAS}

Neste capítulo são descritas as entrevistas efetuadas com os gestores comerciais. As entrevistas foram gravadas e posteriormente transcritas. As questões foram elaboradas tendo como base o referencial teórico previamente 
estruturado, com o objetivo de avaliar os aspectos mais relevantes da gestão comercial através de agentes de vendas, as rotinas dos profissionais entrevistados e determinar os pontos críticos encontrados na exportação através desse canal de vendas.

Com a finalidade de manter a identidade dos gestores e suas respectivas empresas em anonimato, foi adotado o termo "Empresa " $\mathrm{A}$ ", representando o entrevistado e sua empresa, modificando a letra escolhida para dar sequência na nomenclatura dos entrevistados.

\section{FORMA COMO É FEITA A GESTÃO COMERCIAL POR MEIO DO AGENTE DE VENDAS}

A primeira questão, sobre a gestão comercial, foi definida com a finalidade de introduzir o assunto aos entrevistados, fazendo com que os mesmos se situassem com relação a quais seriam os tópicos analisados de forma mais genérica.

\section{a) Empresa "A"}

A gestão comercial da empresa " $A$ " através de agentes de vendas está baseada no relacionamento do gestor comercial com tais agentes. Essa relação é construída e mantida através de contatos semanais por telefone ou e-mail. Esses contatos periódicos têm como finalidade o conhecimento dos negócios em andamento e o acompanhamento das atividades do agente, buscando, assim, manter a informação atualizada junto à equipe interna da empresa.

b) Empresa "B"

O gestor se reúne uma vez por mês com a diretoria para analisar a atuação e os resultados dos agentes de vendas. Diariamente, a equipe interna mantém contato com os agentes, discutindo a respeito de clientes novos, prospecção de negócios, negociações em andamento, desenvolvimento de produto e embarque de mercadorias.

\section{c) Empresa "C"}

Historicamente, o agente de vendas da empresa " $C$ " trabalhava sem um acompanhamento próximo da organização. Ele possuía uma lista de preços em dólares e uma política comercial simples e limitada, as quais eram as ferramentas para o agente efetuar as vendas. Desde o início de 2014, o gestor está buscando se aproximar dos agentes de vendas, tentando identificar as dificuldades que os agentes encontram e a maneira como cada mercado trabalha para, dessa forma, atuar com ações pontuais junto aos agentes, auxiliando-os em negociações, sanando eventuais dificuldades enfrentadas e dando mais flexibilidade para negociações conjuntas. Outra nova postura comercial que o gestor está buscando implementar na empresa é a proximidade do próprio gestor com os clientes de exportação. Para tanto, o gestor tem procurado entrar em contato com os clientes para aprofundar o relacionamento da empresa com os mesmos.

d) Empresa "D"

A empresa trabalha com apenas um agente de vendas. Esse agente trabalha segundo o direcionamento dado pela empresa, seguindo o planejamento comercial definido pela mesma. Por se tratar de um novo agente, o seu trabalho ainda está no período de prospecção, porém o mesmo já efetuou algumas 
vendas para novos clientes. A empresa fica responsável por dar treinamento técnico contínuo, pois, no segmento em que a empresa atua (mercado automotivo de reposição), existem diversas questões técnicas e de modelos de veículos que demandam um conhecimento mínimo para efetuar as vendas. Considerando as informações técnicas que o agente ainda não possui, existe um analista comercial interno que lhe dá suporte regular para sanar eventuais dúvidas com relação ao mix de produtos, aplicações de produtos e características técnicas de produtos.

\section{e) Empresa "E"}

A empresa " $E$ " possui um planejamento estratégico desenvolvido por sua diretoria. Esse planejamento é informado ao gestor de operações internacionais que, por sua vez, desenvolve um planejamento tático. Uma das principais questões abordadas no planejamento tático é a escolha do canal de vendas para cada mercado. Com base nisso, o gestor opta por trabalhar por meio de agente ou de forma direta. Caso o gestor opte por trabalhar com um agente, ele definirá uma meta de vendas de acordo com o conhecimento do potencial de mercado, dividindo a meta anual por meses, informando-a ao agente e fazendo o acompanhamento mensal dos resultados. Considera-se o fato de que todos os mercados de exportação devem contribuir para o atingimento de uma meta macro de exportação informada pela direção no planejamento estratégico.

\section{f) Empresa " $F$ "}

O agente de vendas na exportação tem papel de representar a empresa no mercado-alvo, como se a empresa estivesse presente no mercado. A gestão é feita através da capacitação do agente, para que ele seja a "cara" da empresa. Ele possui a lista de preços e efetua a venda, passando o pedido para a empresa depois de concluída a negociação com o cliente. $O$ agente trabalha com comissão variável, possuindo certa flexibilidade na negociação. Quanto maior o preço que o agente praticar, maior é a sua comissão. Consequentemente, quando o agente trabalha com preços inferiores, obtém menor comissão.

Nota-se que na primeira questão os entrevistados explanaram superficialmente sobre o que eles acreditam que seja a gestão comercial dos agentes de vendas. Devido a um entendimento pessoal do que é gestão comercial de agentes, percebe-se que apenas dois pontos foram citados por mais de um gestor: i) o acompanhamento das negociações com clientes; e ii) que a empresa é responsável pelo treinamento técnico do agente. Acredita-se que os fatores comentados por apenas um entrevistado também possam ser válidos para outros gestores, porém cada um mencionou o que acreditava ser o mais relevante na gestão comercial.

\section{PRINCIPAIS VANTAGENS DA VENDA ATRAVÉS DE AGENTES DE VENDAS}

Esta seção apresenta os principais benefícios percebidos pelos mesmos na atuação através de agentes de vendas.

a) Empresa "A"

As principais vantagens citadas pelo gestor de exportação da empresa " $A$ " foram as seguintes: i) velocidade de penetração no mercado-alvo, em virtude de o agente já possuir uma carteira de clientes ativa; ii) nenhum investimento para 
abertura do mercado, mantendo o custo fixo zerado, apenas trabalhando com comissionamento sobre as vendas; iii) confiabilidade no agente, pois, na sua grande maioria, os agentes vêm por indicações de empresas do segmento; iv) conhecimento do mercado por parte do agente, dessa forma protegendo a empresa de entrar em negócios arriscados; v) redução da equipe interna, uma vez que o agente fica responsável por acompanhar entregas, verificar embarques e resolver eventuais problemas que podem acontecer em uma venda (devoluções, problemas de qualidade, embalagem, etc.); e vi) obtenção de dados das empresas concorrentes, histórico de vendas e preços praticados.

\section{b) Empresa "B"}

Para o gestor, a principal vantagem é o fato de o agente já se encontrar no mercado-alvo, possuindo uma rede de contatos e ganhando assim velocidade na abertura de novos clientes para a empresa.

\section{c) Empresa " $\mathrm{C}$ "}

Uma das principais vantagens da atuação através do agente de vendas citada pelo gestor comercial é o fato de o agente já possuir uma carteira de clientes ativa no momento em que foi contratado pela empresa. Isso facilita a abertura de clientes, pois o agente já goza de credibilidade no mercado em que atua, em virtude do relacionamento que já construiu. Esse conhecimento acaba por dar mais segurança para ambas as partes, tanto para o cliente, pois já confia no agente, quanto para a empresa, que sabe que o agente já conhece o cliente, evitando assim problemas com pagamentos.

d) Empresa " $D$ "

A principal vantagem da gestão de vendas através do agente de vendas é o fato de ele já ter uma carteira de clientes ativos. Outro fator positivo é o fato de o agente comercial estar inserido em um mercado no qual os concorrentes também atuam, municiando a empresa de informações mercadológicas a respeito de clientes, preços praticados, políticas comerciais, entre outras informações.

\section{e) Empresa "E"}

Para o gestor da empresa "E", a principal vantagem de atuar com o agente é o fato de ser menos oneroso para a empresa. Trabalhar com esse canal não envolve significativo investimento inicial para abertura de novos mercados, não trazendo custos fixos para a empresa, apenas remuneração mediante resultado. Isso também acaba por ser interessante para o agente, pois, na grande maioria dos casos, ele também irá trabalhar para outras empresas que irão aumentar a sua remuneração.

\section{f) Empresa " $\mathrm{F}$ "}

A principal vantagem considerada pelo gestor comercial da empresa é o fato de o agente de vendas conseguir atingir todo tipo de cliente, isto é, clientes de maior porte e de menor porte, diferentemente de atuação por distribuidores, que irão atingir apenas os clientes de menor porte. O Quadro 1 apresenta os principais benefícios do uso de agentes citados pelos entrevistados. 
Quadro 1 - Benefícios do uso de agentes

\begin{tabular}{|l|c|c|c|c|c|c|c|}
\hline \multirow{2}{*}{ Principais benefícios } & \multicolumn{5}{c|}{ Entrevistados } & Soma \\
\cline { 2 - 8 } & EA & EB & EC & ED & EE & EF & \\
\hline $\begin{array}{l}\text { Conhecimento do mercado por parte } \\
\text { do agente }\end{array}$ & $\mathrm{X}$ & $\mathrm{X}$ & $\mathrm{X}$ & $\mathrm{X}$ & & & 4 \\
\hline $\begin{array}{l}\text { Velocidade de penetração no } \\
\text { mercado-alvo }\end{array}$ & $\mathrm{X}$ & $\mathrm{X}$ & & $\mathrm{X}$ & & & 3 \\
\hline $\begin{array}{l}\text { Baixo investimento para abertura do } \\
\text { mercado }\end{array}$ & $\mathrm{X}$ & & & & $\mathrm{X}$ & & 2 \\
\hline $\begin{array}{l}\text { Confiança da empresa no agente } \\
\text { Credibilidade do agente no mercado- } \\
\text { alvo }\end{array}$ & $\mathrm{X}$ & & $\mathrm{X}$ & & & & 2 \\
\hline $\begin{array}{l}\text { Informações prestadas pelo agente } \\
\text { sobre o mercado }\end{array}$ & $\mathrm{X}$ & & & $\mathrm{X}$ & & & 2 \\
\hline $\begin{array}{l}\text { Possibilidade de o agente atingir todas } \\
\text { as categorias de clientes do mercado }\end{array}$ & & & & & & $\mathrm{X}$ & 1 \\
\hline Soma & 5 & 2 & 3 & 3 & 1 & 1 & 15 \\
\hline
\end{tabular}

Fonte: Elaborado pelos autores.

Percebe-se no Quadro 1 que os entrevistados, ao serem questionados sobre os fatores positivos da atuação comercial através de agentes de vendas, listaram na sua maioria o conhecimento do mercado por parte do agente, o que está diretamente ligado ao segundo fator mais constatado na pesquisa, que é a velocidade de penetração no mercado. Outros fatores também citados por mais de um gestor são o baixo investimento necessário para iniciar o trabalho com o agente, a confiança que a empresa já possui no trabalho do profissional e as informações prestadas pelo agente à empresa.

\section{PRINCIPAIS DESVANTAGENS DA VENDA ATRAVÉS DE AGENTES DE VENDA}

Para verificar os pontos críticos na atuação da venda através de agentes, os entrevistados foram questionados sobre os aspectos negativos da escolha. Foi esclarecido que os fatores deveriam estar relacionados com o canal de vendas e não com a atuação pontual do profissional com o qual se está trabalhando.

a) Empresa "A"

De acordo com o gestor da empresa " $A$ ", as principais desvantagens da utilização de agentes de vendas são: i) o agente é que mantém o relacionamento com o cliente, ficando assim em suas mãos o andamento das negociações; ii) o agente controla as informações que vêm do mercado e a empresa fica à mercê do ponto de vista do agente; e iii) o agente gera um custo variável, causando um efeito direto no preço de venda do produto e podendo, eventualmente, inviabilizar a venda para um mercado muito competitivo. Portanto, o sucesso comercial no mercado depende em parte do agente, cabendo salientar que, eventualmente, a atuação do agente pode não estar em sintonia com a estratégia comercial da empresa.

b) Empresa "B"

A principal desvantagem se trata da falta de informação, pois, de acordo com o gestor, quem possui a informação é o agente, mantendo a empresa refém 
daquilo que ele deseja e acha pertinente a empresa saber. Muitas vezes, em virtude desse controle das informações, o cliente pertence ao agente e não à empresa, podendo, dessa forma, migrar para um concorrente, caso o agente seja desvinculado da empresa.

\section{c) Empresa " $\mathrm{C}$ "}

Levando-se em consideração o caso específico do agente que atende a América Latina, a principal desvantagem é a distância física do agente aos clientes, pois o agente é responsável por visitar clientes em diversos mercados e países. Essa distância torna as visitas do agente menos frequentes, possibilitando assim a entrada de concorrentes que tenham maior frequência de visitas. Outro ponto negativo proveniente dessa distância é a dificuldade de prospecção de novos clientes, pois o agente não reside no mercado em que atua, limitando, assim, seu conhecimento a respeito do mesmo.

d) Empresa "D"

Uma das principais desvantagens da atuação do agente de vendas citados pelo gestor da empresa " $D$ " deve-se ao fato de o mesmo residir no Brasil, fazendo com que diminua sua frequência de visita aos clientes, o que acarreta menor suporte técnico aos mesmos.

Outra desvantagem é o fato de a remuneração do agente ser variável sobre o preço de vendas, elevando o custo do produto e podendo inviabilizar as vendas. Também é considerado desvantagem o fato de o agente ser o detentor das informações de mercado, correndo-se assim o risco de o mesmo apenas informar aquilo que seja benéfico para ele.

e) Empresa "E"

A principal desvantagem de trabalhar com agentes mencionada pelo gestor da empresa "E" é o fato de a empresa não poder contar com total comprometimento por parte do agente, em virtude de ele trabalhar de forma não exclusiva. Por esse motivo, o seu resultado depende do potencial de remuneração que cada empresa pode trazer. $O$ gestor também informou que 0 produto com que a empresa trabalha não tem grande valor agregado, acarretando desinteresse por parte do agente em trabalhar de forma mais intensa para a empresa.

Além desse fator, outro ponto negativo é o fato de a empresa acabar ficando refém das informações fornecidas pelo agente. $O$ gestor também indicou como desvantagem a maneira como tem que tratar os agentes no momento da cobrança por resultados. Essa cobrança tem que ser mais branda, pelo fato de o agente não ser um funcionário da empresa.

f) Empresa " $F$ "

A gestora comercial não percebe desvantagem em trabalhar com agentes de vendas. 
Quadro 2-Principais desvantagens do uso de agentes de venda

\begin{tabular}{|c|c|c|c|c|c|c|c|}
\hline \multirow{2}{*}{ Principais desvantagens } & \multicolumn{6}{|c|}{ Entrevistados } & \multirow[t]{2}{*}{ Soma } \\
\hline & EA & EB & EC & ED & $\mathrm{EE}$ & $\mathrm{EF}$ & \\
\hline $\begin{array}{l}\text { O agente controla as informações que } \\
\text { vêm do mercado }\end{array}$ & $x$ & $x$ & $x$ & $x$ & $x$ & & 5 \\
\hline $\begin{array}{l}\text { O agente mantém o relacionamento } \\
\text { com o cliente e não a empresa }\end{array}$ & $x$ & $x$ & $\mathrm{X}$ & & $x$ & & 4 \\
\hline $\begin{array}{l}\text { O agente gera um custo variável, } \\
\text { podendo inviabilizar o preço do } \\
\text { produto no mercado-alvo }\end{array}$ & $x$ & & & $x$ & & & 2 \\
\hline $\begin{array}{l}\text { É difícil controlar a atuação do agente, } \\
\text { em virtude de ele não ser um vendedor } \\
\text { exclusivo }\end{array}$ & & & & $x$ & $x$ & & 2 \\
\hline $\begin{array}{l}\text { O agente controla a estratégia } \\
\text { comercial, definindo para quais clientes } \\
\text { vender ou não }\end{array}$ & $x$ & & & & & & 1 \\
\hline $\begin{array}{l}\text { Distância física do agente ao mercado } \\
\text { atendido }\end{array}$ & & & $\mathrm{X}$ & & & & 1 \\
\hline $\begin{array}{l}\text { Baixa taxa de prospecção de novos } \\
\text { clientes }\end{array}$ & & & $\mathrm{X}$ & & & & 1 \\
\hline $\begin{array}{l}\text { Falta de suporte técnico do agente aos } \\
\text { clientes }\end{array}$ & & & & $x$ & & & 1 \\
\hline $\begin{array}{l}\text { Pode haver desinteresse do agente em } \\
\text { promover mercadorias de menor valor } \\
\text { agregado }\end{array}$ & & & & & $x$ & & 1 \\
\hline $\begin{array}{l}\text { É difícil cobrar o agente por resultados, } \\
\text { em virtude de ele não ser funcionário } \\
\text { da empresa }\end{array}$ & & & & & $x$ & & 1 \\
\hline $\begin{array}{l}\text { Não há desvantagem em trabalhar com } \\
\text { agentes }\end{array}$ & & & & & & $\mathrm{X}$ & 1 \\
\hline Soma & 4 & 3 & 4 & 4 & 5 & 1 & \\
\hline
\end{tabular}

Fonte: Elaborado pelos autores.

Em relação aos pontos negativos de atuar por meio de agentes, dos quatro fatores mais citados, três deles estão diretamente ligados ao fato de o agente não ser um funcionário contratado pela empresa. As desvantagens mais citadas foram o fato de o agente controlar as informações do mercado e de manter o contato direto com o cliente.

Um ponto negativo também citado é o fato de o agente estar distante fisicamente do mercado. Considera-se que isso não é necessariamente um ponto negativo do canal de vendas escolhido, mas sim uma consequência da localização do profissional escolhido.

\section{PROCESSO DE SELEÇÃO DO AGENTE DE VENDAS}

No mercado internacional, é importante considerar os desafios de controle que existem em virtude das diferenças políticas, culturais e econômicas dos mercados, além da distância geográfica dos mesmos. Ao analisar esses pontos críticos, foi elaborada uma questão para a explanação dos entrevistados sobre as metodologias de seleção de agentes de vendas.

\section{a) Empresa "A"}


Quanto à seleção do agente, o entrevistado da empresa " $A$ " informou que o processo seletivo se deu por indicação e posterior entrevista com o profissional escolhido.

b) Empresa "B"

A busca do agente ocorre por meio da localização de canais de venda semelhantes ao da empresa. A empresa localiza outras indústrias que atinjam o mesmo cliente, que atuem no mesmo segmento e que já estejam inseridas em um determinado mercado-alvo. Então busca descobrir quais agentes já representam essas empresas, contatando os gestores das mesmas para a busca de informações. Outro método utilizado para a prospecção de agentes de vendas são as visitas a feiras do segmento nos mercados-alvos. Isso se deve ao fato de muitos agentes visitarem as feiras, facilitando assim o contato da empresa com os mesmos.

\section{c) Empresa " $C$ "}

O agente foi selecionado através de indicação de outra empresa que atua no mesmo segmento de mercado.

\section{d) Empresa " $D$ "}

O gestor comercial procura trabalhar com indicações, pois quando ele possui alguma referência com relação ao trabalho do profissional pode diminuir as chances de contratar alguém que não irá desempenhar o trabalho da maneira esperada. Além disso, é prática comum da empresa entrar em contato com clientes que são atendidos pelo agente e com empresas que já trabalham com o agente, para questionar sobre o atendimento do agente, sua índole, dentre outros fatores.

\section{e) Empresa "E"}

A prospecção do agente por parte do gestor da empresa " $E$ " deve-se ao fato de o gestor ter trabalhado durante um longo período em uma empresa que atinge os mesmos clientes da atual, fazendo com que o mesmo tenha uma grande rede de relacionamento com agentes e clientes por todo o mundo. 0 gestor faz uso desse relacionamento para buscar indicações de agentes que atuam nos mercados-alvo. Além disso, por vezes o gestor opta em prospectar agentes in loco, visitando o mercado-alvo, contatando os principais clientes e listando as principais empresas que atuam no mercado desejado.

\section{f) Empresa " $\mathrm{F}$ "}

O processo de busca e seleção de agentes é feito por meio de busca de outras empresas que atinjam o mesmo público-alvo, que atuem no mesmo segmento e que tenham produtos complementares. Após mapear essas empresas, o gestor entra em contato com as mesmas e solicita informações de agentes que trabalham na região. Caso as empresas não queiram informar, busca-se a informação com os clientes que a empresa já tenha desenvolvido no mercado. 
Quadro 3 - Principais formas de seleção de agentes de venda

\begin{tabular}{|c|c|c|c|c|c|c|c|}
\hline \multirow{2}{*}{ Formas de seleção de agentes } & \multicolumn{6}{|c|}{ Entrevistados } & \multirow{2}{*}{ Soma } \\
\hline & EA & EB & EC & ED & EE & EF & \\
\hline Indicação por network & $x$ & $x$ & $x$ & $x$ & $x$ & & 5 \\
\hline $\begin{array}{l}\text { Contato com empresas do mesmo } \\
\text { segmento, solicitando indicação }\end{array}$ & & $x$ & & $x$ & $x$ & $x$ & 4 \\
\hline $\begin{array}{l}\text { Contato com clientes já atendidos pelo } \\
\text { agente }\end{array}$ & & & & $x$ & $x$ & $x$ & 3 \\
\hline Visitas a feiras do segmento & & $x$ & & & & & 1 \\
\hline Visitas in loco no mercado & & & & & $x$ & & 1 \\
\hline Soma & 1 & 3 & 1 & 3 & 4 & 2 & 14 \\
\hline
\end{tabular}

Fonte: Elaborado pelos autores.

Considerando os fatores citados pelos gestores quando questionados sobre quais são os métodos utilizados para a seleção do agente, foi quase unânime o uso de network. Isso confirma que, no mercado internacional, o relacionamento com profissionais da mesma área é fundamental e que o agente é profissional de confiança, detentor de informações importantes. Muito semelhante ao fator mais citado, os dois seguintes também revelam a indicação, o que reforça a importância das redes de relacionamento.

\section{CONTRATOS COMERCIAIS E PRINCIPAIS FATORES RELACIONADOS}

Como relatado no referencial teórico, é de fundamental importância as empresas trabalharem com contratos comerciais com os agentes. Para analisar o grau de conhecimento e importância dada aos contratos, os entrevistados foram questionados sobre sua utilização e suas principais cláusulas.

\section{a) Empresa "A"}

No momento do fechamento da parceria com o agente, a banca jurídica da empresa desenvolveu o contrato de agenciamento comercial, que foi avaliado e aprovado pelo agente. Os principais cuidados observados no desenvolvimento do contrato foram as cláusulas rescisórias, de remuneração e de abrangência de atuação do agente de vendas.

b) Empresa "B"

A empresa trabalha com contratos de agência, sendo a principal cláusula a meta de vendas do agente, pois, de acordo com o gestor, já é possível desvincular um agente de atender uma determinada carteira de clientes caso ele não alcance as metas pré-determinadas pela empresa. Outra cláusula importante é a da remuneração que, neste caso, acontece de acordo com o resultado de cada negociação, não havendo um percentual fixo de remuneração sobre as vendas.

c) Empresa " $\mathrm{C}$ "

Os principais fatores relacionados no contrato com o agente de vendas são: i) cláusula que estipula que o pagamento de comissão deverá ser efetuado após o fechamento do câmbio da exportação, mediante a entrega de nota fiscal de serviço por parte do agente de vendas; ii) solicitação ao agente que tenha registro no CORE como representante comercial, pois este agente é residente e cidadão brasileiro; iii) cláusula de que o agente não pode trabalhar com empresa 
que seja concorrente direta para evitar conflitos de interesse; e iv) cláusula delimitando a atuação do agente de vendas de forma geográfica.

d) Empresa "D"

Em um primeiro momento, durante um período de experiência, o agente trabalha apenas com um contrato verbal com a empresa. Após alguns meses, o agente verifica se é interessante representar a empresa e se os clientes com os quais atua se interessam pelo produto. Nesse mesmo período a empresa avalia o trabalho do agente, verificando sua efetividade. Caso ambas as partes estejam satisfeitas e dispostas a dar continuidade ao trabalho, é formalizado um contrato, o qual é desenvolvido pelo setor jurídico da empresa.

e) Empresa “E”

A empresa trabalha com contratos para oferecer exclusividade ao agente por região geográfica, além de considerar volumes mínimos de vendas para manter essa exclusividade. Eventual rompimento de contrato é informado com antecedência, de modo a possibilitar que as partes se preparem para mudanças decorrentes da finalização do contrato de agência.

f) Empresa " $F$ "

Quando é estabelecido um contrato, o principal cuidado tomado pela empresa é o estabelecimento da região de atuação do agente para evitar que agentes se sobreponham em mercados em comum. Outra cláusula na qual se tem cuidado especial é a vigência do contrato, de modo que esta não seja extensa ao ponto de prejudicar a inserção em um mercado por má atuação do agente de vendas.

Quadro 4 - Principais fatores relacionados com o contrato de agência

\begin{tabular}{|c|c|c|c|c|c|c|c|}
\hline \multirow{2}{*}{$\begin{array}{l}\text { Principais fatores relacionados com o } \\
\text { contrato de agência }\end{array}$} & \multicolumn{6}{|c|}{ Entrevistados } & \multirow{2}{*}{ Soma } \\
\hline & EA & EB & EC & ED & EE & EF & \\
\hline Cláusula de remuneração & $\mathrm{X}$ & $\mathrm{X}$ & $\mathrm{X}$ & & & & 3 \\
\hline $\begin{array}{l}\text { Cláusula de abrangência geográfica de } \\
\text { atuação }\end{array}$ & $X$ & & $\mathrm{X}$ & & & $x$ & 3 \\
\hline Cláusula de metas de vendas & & $x$ & & & $\mathrm{x}$ & & 2 \\
\hline Contrato verbal & & & & $x$ & & $\mathrm{x}$ & 2 \\
\hline Cláusulas rescisórias & $\mathrm{X}$ & & & & $\mathrm{x}$ & & 2 \\
\hline $\begin{array}{l}\text { Registro no CORE, caso seja residente no } \\
\text { Brasil }\end{array}$ & & & $\mathrm{X}$ & & & & 1 \\
\hline $\begin{array}{l}\text { Cláusula de não permissão de o agente } \\
\text { trabalhar com empresas concorrentes }\end{array}$ & & & $\mathrm{X}$ & & & & 1 \\
\hline Cláusula de exclusividade de venda & & & & & $\mathrm{X}$ & & 1 \\
\hline Políticas comerciais e tabelas de preços & & & & & $\mathrm{x}$ & & 1 \\
\hline Vigência do contrato & & & & & & $\mathrm{X}$ & 1 \\
\hline Soma & 3 & 2 & 4 & 1 & 4 & 3 & 17 \\
\hline
\end{tabular}

Fonte: Elaborado pelos autores.

Percebe-se que os gestores têm conhecimento do contrato de agência, mesmo que não sejam responsáveis por sua elaboração. Esse conhecimento fica evidente ao considerar que, dos seis gestores entrevistados, cinco citaram ao menos duas cláusulas importantes desse tipo de contrato. Outro aspecto 
interessante a salientar são os diferentes tipos de cláusulas comentadas pelos gestores.

\section{PRINCIPAIS FUNÇÕES DESEMPENHADAS PELO AGENTE DE VENDAS}

Para uma gestão comercial eficiente dos agentes internacionais de vendas, é fundamental que o gestor tenha conhecimento de quais são as funções desempenhadas pelos mesmos. Nesta seção são analisadas as principais funções desempenhadas pelos agentes e sua responsabilidade no processo da venda.

a) Empresa "A"

Segundo o gestor da empresa " $A$ ", as principais funções desempenhadas pelos agentes são: i) prospeç̧ão de novos clientes e visitas periódicas aos clientes atuais; ii) negociação com os clientes; iii) acompanhamento das vendas efetuadas, posicionando o cliente com relação às entregas; iv) acompanhamento do mercado, informando possível crescimento, estabilidade ou recessão no mesmo; v) acompanhamento e conferência da documentação de venda; vi) suporte técnico aos clientes; e vii) pós-vendas.

b) Empresa "B"

De acordo com o gestor da empresa " $B$ ", as principais funções desempenhadas pelos agentes são: i) visitação a clientes; ii) negociação; e iii) apoio ao desenvolvimento de produtos, mediante a prestação de informações relevantes de seu mercado de atuação.

c) Empresa " $\mathrm{C}$ "

Segundo o gestor da empresa " $C$ ", as funções desempenhadas pelos agentes de vendas são as seguintes: i) visitação a clientes; ii) visitação a feiras do segmento; iii) negociação com clientes; e iv) prospecção de mercado.

d) Empresa "D"

Segundo o gestor da empresa " $\mathrm{D}$ ", o agente de vendas é responsável pela prospeç̧ão de clientes e por efetuar as vendas. O entrevistado complementou que, em sua empresa, o agente depende do suporte do analista interno para construir as cotações de venda, em virtude da dificuldade enfrentada em conhecer todo o mix de produtos e suas particularidades. Um fator interessante, segundo o entrevistado, seria o agente poder contatar diretamente a engenharia da empresa para discutir a respeito de novos desenvolvimentos ou melhorias nos produtos.

e) Empresa "E"

As obrigações do agente estão vinculadas ao ciclo da venda, incluindo a prospecção do cliente, a efetivação da venda e o pós-vendas. A principal função que atualmente não é desempenhada pelo agente, mas que seria de muita importância para empresa, é o agente trabalhar com uma ferramenta de CRM, gerando informações mais detalhadas e atualizadas dos clientes. Também seria interessante o agente desempenhar pesquisa de mercado de clientes e concorrentes.

f) Empresa " $F$ " 
Segundo o gestor da empresa " $F$ ", é imprescindível que o agente possa dar suporte técnico ao cliente, em virtude do tipo de produto ofertado pela empresa. Além disso, o agente é responsável por suprir a empresa com informações de mercado, tais como crescimento de mercado, concorrentes, produtos, oportunidades, etc.

Quadro 5 - Principais funções dos agentes de venda

\begin{tabular}{|c|c|c|c|c|c|c|c|}
\hline \multirow{2}{*}{ Principais funções do agente de vendas } & \multicolumn{6}{|c|}{ Entrevistados } & \multirow[t]{2}{*}{ Soma } \\
\hline & EA & EB & EC & ED & EE & EF & \\
\hline Prospecção de clientes & 1 & 1 & 1 & 1 & 1 & 1 & 6 \\
\hline Negociação & 1 & 1 & 1 & 1 & 1 & 1 & 6 \\
\hline Informações sobre o mercado & 1 & & 1 & & 1 & 1 & 4 \\
\hline Acompanhamento de vendas e entregas & 1 & & & & & 1 & 2 \\
\hline Suporte técnico/ pós-vendas & 1 & & & 1 & 1 & 1 & 4 \\
\hline Acompanhamento de documentação & 1 & & & & & & 1 \\
\hline Visitação a feiras do segmento & & & 1 & & & & 1 \\
\hline CRM de clientes & & & & & 1 & & 1 \\
\hline Soma & 6 & 2 & 4 & 3 & 5 & 5 & 25 \\
\hline
\end{tabular}

Fonte: Elaborado pelos autores.

Ao analisar as respostas dos entrevistados sobre as funções desempenhadas pelos agentes, percebe-se que a função do agente é basicamente prospectar clientes, negociar e prestar à empresa representada informações sobre o mercado.

\section{FORMAS DE AVALIACCÃO DOS AGENTES DE VENDAS}

Para avaliar o trabalho do agente, é necessário estabelecer metas e objetivos a serem cumpridos. Por esse motivo, os entrevistados explanaram a respeito de quais são os seus métodos para analisar e avaliar o trabalho dos agentes de vendas.

a) Empresa "A"

O desempenho do agente é avaliado por seus resultados comerciais: vendas efetuadas, crescimento de vendas e abertura de novos clientes. $O$ agente possui metas de vendas que são analisadas mensalmente pela empresa. Essas metas são estabelecidas de acordo com a necessidade de faturamento da empresa, não levando em consideração o potencial do mercado ou o histórico de vendas.

b) Empresa "B"

Os agentes de vendas possuem metas de faturamento. Essas metas são avaliadas mensalmente e estabelecidas uma vez por ano, durante o planejamento estratégico da empresa. Cada meta é negociada diretamente com cada agente de vendas. $O$ estabelecimento das metas leva em conta o histórico de vendas do ano anterior e perspectiva de crescimento traçada no planejamento da empresa.

c) Empresa " $\mathrm{C}$ " 
A avaliação do agente se dá através de dois indicadores: faturamento e margem de contribuição. A meta de faturamento é construída com base no histórico de vendas de três anos, de forma mensal, e levando-se em consideração o crescimento estipulado pela direção da empresa. O agente é informado da meta todo início de mês, porém a meta é apenas sugerida. Nesse sentido, de acordo com o gestor da empresa " $C$ ", devido ao fato de o agente se enquadrar como representante, legalmente não é possível cobrar metas de vendas. Já a análise da margem de contribuição se dá pela equipe interna, não sendo controlada pelo agente de vendas.

d) Empresa "D"

A empresa " $D$ " trabalha com metas mensais de faturamento para o agente, pelo fato de o mesmo estar prospectando novos mercados e a empresa ainda não possuir histórico de vendas. O gestor define uma meta razoável, de acordo com o tempo de trabalho desenvolvido pelo agente e o potencial do mercado. Com o passar do tempo, as metas vão se tornando maiores, porém sempre negociadas com o agente para que estejam de acordo com o potencial de mercado visualizado pelo mesmo. O gestor considera que a meta, ao mesmo tempo, deve ser atingível e desafiadora para incentivar o trabalho do agente.

e) Empresa " $E$ "

O agente é avaliado por seu resultado comercial (vendas). Esse resultado está vinculado ao vendedor interno responsável por acompanhar o agente em questão. Além disso, o agente também é avaliado pelo número de novos clientes e pela margem de contribuição obtida em suas vendas. No âmbito dos fatores intangíveis, o principal aspecto que é levado em consideração por parte do gestor comercial é a velocidade de resposta do agente. É fundamental para o bom relacionamento entre a empresa e o agente que o mesmo tenha uma resposta rápida aos contatos feitos pela empresa, assegurando velocidade e confiabilidade nas informações prestadas.

f) Empresa " $F$ "

A empresa " $\mathrm{F}$ " divide suas metas por país, considerando o histórico de vendas e projetando o crescimento objetivado pela companhia. 0 acompanhamento das metas acontece de forma interna, mensalmente, e a avaliação do trabalho do agente acontece de forma trimestral, evitando maiores distorções em virtude de sazonalidades do mercado e pelo fato de algumas negociações demorarem mais tempo do que no mercado interno.

Quadro 6 - Formas de avaliação de agentes de venda

\begin{tabular}{|c|c|c|c|c|c|c|c|}
\hline \multirow{2}{*}{ Formas de avaliação dos agentes de venda } & \multicolumn{6}{|c|}{ Entrevistados } & \multirow{2}{*}{ Soma } \\
\hline & EA & EB & EC & ED & EE & EF & \\
\hline Volume de vendas & $\mathrm{X}$ & $x$ & $x$ & $x$ & $\mathrm{x}$ & $x$ & 6 \\
\hline Abertura de novos clientes & $x$ & & & & $x$ & & 2 \\
\hline Margem de contribuição & & & $x$ & & $\mathrm{X}$ & & 2 \\
\hline Quantidade de produtos vendidos & & & & & $x$ & & 1 \\
\hline Soma & 2 & 1 & 2 & 1 & 4 & 1 & 11 \\
\hline
\end{tabular}

Fonte: Elaborado pelos autores. 
Percebe-se no Quadro 6 que o único fator unânime entre os entrevistados foi o volume de vendas, seguido pela abertura de novos clientes e pela margem de contribuição.

\section{PONTOS DE MELHORIA NA GESTÃO COMERCIAL DOS AGENTES DE VENDA}

A questão de fechamento da entrevista foi desenvolvida com o objetivo de identificar pontos de melhoria que os gestores acreditam que sejam importantes para a gestão comercial dos agentes de vendas. Os resultados são apresentados a seguir.

a) Empresa "A"

O gestor comercial da empresa " $\mathrm{A}$ " entende que, para melhorar a gestão de vendas através do agente, dever-se-ia buscar um maior número de agentes para as áreas descobertas. Além disso, a empresa deveria investir mais em pesquisa de mercado, podendo medir com maior eficiência o potencial de cada mercado e, consequentemente, os resultados obtidos pelos agentes de vendas.

b) Empresa "B"

De acordo com o gestor comercial da empresa "B", o que poderia ser aprimorado é o relacionamento da empresa com os principais clientes de exportação, não deixando apenas nas mãos dos agentes os contatos e as negociações. A empresa já está buscando aproximar-se dos clientes através de um maior número de viagens de funcionários ao mercado externo, visando aprofundar laços com clientes estratégicos. Outra função que o agente poderia desempenhar com maior eficiência é a pesquisa de mercado, trazendo maior volume e qualidade de informações de clientes, concorrentes e oportunidades de negócios.

\section{c) Empresa " $\mathrm{C}$ "}

Como melhoria, o gestor citou o acompanhamento mais próximo do agente, analisando negócio a negócio. Além disso, foi citada a necessidade de uma maior aproximação do gestor com os clientes, aumentando seus vínculos com a empresa. Outros pontos de melhoria citados foram a intensificação na prospecção de novos clientes e o aprimoramento da pesquisa de mercado por parte do agente.

d) Empresa " $D$ "

O gestor comercial da empresa " $D$ " considera importante o desenvolvimento de melhores ferramentas de vendas para os agentes, tais como material informativo, catálogos, site atualizado, amostras, tabelas de preços, entre outras. Essas ferramentas ajudariam a suprir eventuais carências dos agentes, até que os mesmos desenvolvessem o conhecimento necessário para atuar de forma mais independente. Além disso, é fundamental que os agentes venham a se qualificar tecnicamente para poder ser mais eficaz em seu resultado comercial.

e) Empresa "E"

Considerando o cenário de diminuição de investimento na área comercial por parte da empresa, o gestor comercial necessitou diminuir em grande número suas viagens aos mercados de exportação. A retomada dessas viagens é vista 
como uma oportunidade de melhoria para evitar a baixa de vendas ou a perda de oportunidades no mercado externo.

f) Empresa " $F$ "

O principal aprimoramento na gestão comercial citado pelo entrevistado da empresa " $F$ " é a maior presença do gestor comercial nos mercados, visitando os agentes, treinando os agentes, visitando clientes e potencializando negociações. Segundo o entrevistado, isso aumenta a credibilidade da empresa e auxilia no fechamento de negócios.

Quadro 7 - Pontos de melhoria na gestão comercial dos agentes de venda

\begin{tabular}{|c|c|c|c|c|c|c|c|}
\hline \multirow{2}{*}{$\begin{array}{l}\text { Pontos de melhoria na gestão comercial dos } \\
\text { agentes de venda }\end{array}$} & \multicolumn{6}{|c|}{ Entrevistados } & \multirow{2}{*}{ Soma } \\
\hline & EA & EB & EC & ED & EE & EF & \\
\hline Maior aproximação da empresa aos clientes & & $x$ & $x$ & & $x$ & $x$ & 4 \\
\hline Maior proximidade entre empresa e agente & & & $x$ & & $x$ & $x$ & 3 \\
\hline $\begin{array}{l}\text { Maior número de informações de mercado } \\
\text { por parte do agente }\end{array}$ & & $\mathrm{X}$ & $x$ & & & & 2 \\
\hline $\begin{array}{c}\text { Maior presença do gestor da empresa no } \\
\text { mercado }\end{array}$ & & & & & $x$ & $x$ & 2 \\
\hline Aumento do número de agentes & $\mathrm{x}$ & & & & & & 1 \\
\hline $\begin{array}{c}\text { Maior investimento em pesquisa de mercado } \\
\text { por parte da empresa }\end{array}$ & $\mathrm{X}$ & & & & & & 1 \\
\hline $\begin{array}{l}\text { Melhores ferramentas para o agente, tais } \\
\text { como catálogos, site e amostras }\end{array}$ & & & $\mathrm{X}$ & & & & 1 \\
\hline Treinamentos técnicos para os agentes & & & & $\mathrm{X}$ & & & 1 \\
\hline Soma & 2 & 2 & 4 & 1 & 3 & 3 & 15 \\
\hline
\end{tabular}

Fonte: Elaborado pelos autores.

Em relação aos pontos de melhoria na gestão comercial dos agentes de venda, os principais fatores citados foram a maior aproximação da empresa com os clientes e com os agentes. O primeiro fator está diretamente ligado aos pontos negativos listados pelos entrevistados, que na sua maioria estão vinculados ao fato de o agente ser o detentor de informações e um elemento-chave no relacionamento da empresa com os clientes. O segundo fator, adicionalmente, facilita a avaliação do trabalho do agente, bem como o seu alinhamento às expectativas da empresa exportadora.

\section{DISCUSSÃO DOS RESULTADOS}

Nesta seção são confrontadas as informações oriundas do referencial teórico com as informações obtidas nas entrevistas e são localizados eventuais pontos de melhoria para a prática da gestão comercial por meio de agentes.

Quando questionados sobre a forma como é feita a gestão comercial dos agentes, os entrevistados citaram a importância do acompanhamento dos agentes e do estabelecimento de mecanismos de avaliação. Isso vem ao encontro das ideias de Katsikea e Morgan (2003), que consideram fundamental o acompanhamento do agente pelo gestor, com práticas como treinamentos e avaliações de desempenho periódicas. 
Cavusgil, Knight e Riesenberger (2010) consideram que a venda através de agentes é vantajosa no sentido de permitir à empresa ter um relacionamento mais próximo com o cliente, pois a venda ocorre de forma direta, sem intermediadores na cadeia de distribuição. No entanto, isso não foi confirmado na pesquisa. Pelo contrário, o principal ponto negativo citado pelos entrevistados foi o baixo controle da atividade dos agentes por parte das empresas e a falta de repasse de informações do mercado por parte do agente, o que evidencia uma assimetria de informações entre as empresas e os agentes. Cabe salientar que a assimetria de informações é mencionada em diversos estudos como um fator relevante para a coordenação de cadeias de suprimentos (PEZESHKI et al., 2013) e tem relação também com o processo de definição dos preços de venda (DAl; CHAO, 2016). No caso específico da relação entre empresas exportadoras e agentes internacionais de venda, essa assimetria de informações poderia ser reduzida se as empresas melhorassem o acompanhamento dos agentes e dos clientes no mercado externo. Nesse sentido, as ferramentas de CRM, mencionadas nas entrevistas, podem ser úteis.

O principal ponto positivo na atuação comercial através de agentes citado pelos entrevistados é o fato de o agente conhecer o mercado-alvo, o que gera velocidade de penetração e baixo investimento. Isso se mostra de acordo com a afirmação de Minervini (2001) de que a principal vantagem é o baixo investimento, seguido da velocidade de ganho de mercado, pois o agente conhece o mercado e é conhecido no mesmo. Considerando essas principais vantagens, é possível concluir que as empresas com as quais foi realizada a pesquisa deveriam fazer mais uso de agentes para ampliar sua atuação no mercado internacional, pois todas vislumbram potencial de crescimento de exportação e têm orçamento limitado para isso.

Quando os gestores foram questionados sobre os métodos utilizados para a contratação de agentes, os mesmos listaram a utilização de network e contato com empresas que já atendem o segmento-alvo, mas que não sejam concorrentes, para solicitar indicações. Isso condiz com Minervini (2008) e com Dalrymple, Cron e Decarlo (2004), que consideram que um agente de vendas eficiente representa empresas que não competem entre si, mas se complementam. Por outro lado, Minervini (2008) lista diversas outras fontes para prospectar agentes, tais como: organismos oficiais, sites, associações de fabricantes de produtos similares, exportadores de produtos complementares aos da empresa, câmaras de comércio bilaterais, feiras, rodadas de negócios, missões empresariais e diretórios especializados de importadores. Algumas dessas opções foram pouco ou nada lembradas pelos gestores, evidenciando que existem outras maneiras para prospecção de agentes não utilizadas que poderiam facilitar a identificação do profissional mais qualificado.

No sentido de dar segurança para a empresa e para o agente, de acordo com Murta (2013), é fundamental a construção de um contrato bilateral entre as partes envolvidas. Os gestores têm conhecimento dessa necessidade. Todos trabalham com contratos e o seu conhecimento sobre as cláusulas é fundamental para auxiliá-los na gestão comercial. Porém, os gestores não são responsáveis pela elaboração dos contratos, a qual cabe ao setor jurídico das empresas.

Ao discorrerem sobre as funções desempenhadas pelos agentes, os gestores mencionaram apenas atividades operacionais de venda. Entretanto, como contraponto, Castro (2003) considera que as atribuições de acompanhamento do 
mercado e de busca de informações são fundamentais nas atividades dos agentes. Adicionalmente, uma troca de informações mais eficientes é uma aspecto-chave para a coordenação de cadeias de suprimentos (Pezeshki et al., 2013). Essa pode ser considerada uma oportunidade de melhoria para as empresas, que devem estruturar um melhor fluxo informacional envolvendo os agentes internacionais de venda e seus clientes no mercado externo, de modo a apoiar seu processo de tomada de decisões de internacionalização.

Diretamente ligados às funções desempenhadas pelos agentes estão os métodos de avaliação dos mesmos. Em relação a esse ponto, a metade dos entrevistados avalia apenas o volume de vendas. Porém, para Stanton e Spiro (2000), analisar apenas o volume de vendas pode não fornecer dados suficientes. É importante considerar vendas por clientes, produtos e a lucratividade da venda, sendo esta outra oportunidade de melhoria a ser considerada pelas empresas.

Ficou evidenciado que os entrevistados possuem conhecimento de como deve ser efetuada a gestão comercial, porém, por serem responsáveis por diversas outras funções nas empresas, acabam fazendo uma gestão superficial dos agentes internacionais de venda. É possível aprofundar em ferramentas de controle, relacionamento com os agentes, visitas a mercados e clientes, métodos de busca e seleção de agentes, dentre outros aspectos. Para isso, é necessário que as empresas invistam mais tempo e recursos no gerenciamento das atividades realizadas pelos agentes internacionais de vendas.

\section{CONCLUSÕES}

Através desta pesquisa foi possível identificar alguns padrões que se repetem nas exportações através de agentes internacionais de vendas. Em sua grande maioria, os gestores fazem uso de ferramentas de gestão, tais como metas de faturamento e vendas, e reuniões periódicas com os agentes. Porém, os gestores poderiam fazer uso de diversas outras ferramentas de controle para tornar a gestão mais eficiente. Dentre os principais fatores revelados, tanto pela revisão teórica quanto pelas entrevistas com os profissionais da área, ficou evidenciado que o papel do gestor comercial é fundamental para o sucesso do agente de vendas. Nesse sentido, os gestores poderiam potencializar os resultados dos agentes mediante uma maior aproximação com os mesmos e também com os clientes no mercado externo.

Ao analisar os pontos positivos e negativos da utilização de agentes de vendas, também é possível encontrar algumas semelhanças entre os resultados da pesquisa e a literatura analisada. Por exemplo, os entrevistados afirmaram de forma unânime que as empresas perdem informações de mercado ao atuarem por meio de agentes de vendas, sendo esse um ponto crítico na gestão desse canal. Porém, por outro lado, fica claro que o agente é um profissional necessário para o crescimento das vendas em determinadas circunstâncias, tais como em mercados dos quais a empresa está distante e busca rápido crescimento com baixo investimento. A experiência do agente no mercado em que ele está inserido ajuda a aumentar a velocidade de penetração, minimizando o investimento e diminuindo o risco de inadimplência.

Dentre os pontos de melhoria que podem ser adotados na gestão comercial através de agentes, sugere-se aumentar o investimento em pesquisas de 
mercado por parte das empresas, pois é fundamental que as mesmas tenham informações confiáveis de cada mercado, de modo a poder avaliar corretamente o trabalho dos agentes, bem como estipular metas adequadas a cada mercado. Além de informações mercadológicas, também ficou evidenciado que as empresas devem proporcionar para os gestores comerciais a possibilidade de acompanhamento in loco nos mercados com atuação através de agentes. Isso tem como finalidade direcionar, treinar e aperfeiçoar o trabalho do agente, bem como estreitar a relação com os principais clientes, evitando uma situação de risco de perda de clientes em uma possível mudança de agente de vendas.

\section{LIMITAÇÕES DE PESQUISA E SUGESTÃO PARA ESTUDOS FUTUROS}

Devido à pesquisa ter tido abordagem qualitativa, automaticamente devem ser consideradas algumas limitações. A primeira delas diz respeito ao tamanho da amostra, nitidamente menor do que em pesquisas quantitativas, abrindo possibilidade para uma visão limitada do cenário em estudo. A segunda está no fato de a análise estar vinculada e à mercê de interpretações pessoais do entrevistador.

Outra limitação a ser ressaltada é o fato de as empresas selecionadas não terem a exportação como principal atividade. Com isso, acaba sendo destinado pouco tempo por parte dos gestores ao acompanhamento das atividades dos agentes, o que também limita seus esforços para a implantação de ferramentas de gestão e para a avaliação dos resultados obtidos. 


\title{
Exports through sales agents from the viewpoint of medium-sized companies located in Caxias do Sul
}

\begin{abstract}
The present research aimed to investigate the main positive and negative points related to international sales agents' utilization from the point of view of Caxias do Sul medium-sized export companies' managers. To do so, an exploratory qualitative research was conducted by interviewing six managers through a semi structured script of questions. The interviews' results were subjected to content analysis, which identified that the commercial management of the agents may be performed in several ways, through goals, performance indicators, interpersonal relationship, contracts and commercial routines, and that commercial success is related to the performance of the sales manager. As positive points of international sales agents' utilization the need of low investment by export companies and the fast penetration into new markets were identified. On the other hand, the identified negative points mentioned the eventual loss of control and the distance to customers, depending on how the relationship with the agents is conducted.
\end{abstract}

KEYWORDS: Sales Management. Exports. International Sales Agent. 


\section{REFERÊNCIAS}

BALDAUF, A.; CRAVENS, D. W.; GRANT, K. Consequences of sales management control in field sales organizations: a cross-national perspective. International Business Review, v. 11, n. 5, p. 577-609, 2002. crossref

BARDIN, L. Análise de conteúdo. 3. ed. Lisboa: Edições 70, 2000.

BITTAR, C. A. Contratos comerciais. 4. ed. Rio de Janeiro: Forense Universitária, 2005.

CASTRO, J. A. Exportação: aspectos práticos e operacionais. 5. ed. São Paulo, SP: Aduaneiras, 2003.

CASTRO, J. A. Exportação: aspectos práticos e operacionais. 8. ed. São Paulo: Aduaneiras, 2011.

CAVUSGIL, S. T.; KNIGHT, G. A.; RIESENBERGER, J. R. Negócios internacionais: estratégia, gestão e novas realidades. São Paulo: Pearson, 2010.

CORTIÑAS LOPEZ, J. M.; GAMA, M. Comércio exterior competitivo. 2. ed. São Paulo: Aduaneiras, 2005

DALRYMPLE, D. J.; CRON, W. L.; DECARLO, T. E. Sales management. 8. ed. New York: J. Wiley, 2004.

DAI, Y.; CHAO, X. Price delegation and sales force contract design with asymmetric risk aversion coefficient of sales agentes. International Journal of Production Economics, v. 172, p. 31-42, 2016. crossref

GARCIA JR., A. A. Como representar bens e serviços estrangeiros no Brasil. 2. ed. São Paulo: Aduaneiras, 2001.

GEERSBRO, J.; RITTER, T. Antecedents and consequences of sales representatives relationship termination competence. Journal of Business and Industrial Marketing, v. 28, n. 1, p. 41-49, 2013. crossref

HONEYCUTT, E. D.; FORD, J. B.; SIMINTIRAS, A. C. Sales Management: A Global Perspective. New York: Routledge, 2003. 
KATSIKEA, E.; MORGAN, R. Exploring export sales management practices in smalland medium-sized firms. Industrial Marketing Management, v. 32, n. 6, p. 467480, 2003. crossref

KOTABE, M.; HELSEN, K. Administração de marketing global. São Paulo: Atlas, 2000.

LAZEAR, E. P. The impatient sales person and the delegation of pricing authority. Research in Economics, v. 69, p. 63-74, 2015. crossref

MALHOTRA, N. K. Introdução à pesquisa de marketing. São Paulo: Pearson, 2005.

MCNEILLY K.; LAWSON, M. Navigating Through Rough Waters: The Importance of Trust in Managing Sales Representatives in Times of Change. Industrial Marketing Management, v. 28, n. 1, p. 37-49, 1999. crossref

MINERVINI, N. O exportador. 3. ed. São Paulo: Makron Books, 2001.

MINERVINI, N. O exportador: ferramentas para atuar com sucesso no mercado internacional. 5. ed. São Paulo: Pearson Prentice Hall, 2008.

MURPHY, W. H.; NING, L. A multi-nation study of sales manager effectiveness with global implications. Industrial Marketing Management, v. 41, n. 7, p. 11521163, 1999. crossref

MURTA, R. O. Princípios e contratos em comércio exterior. 2. ed. São Paulo: Saraiva, 2013.

PEZESHKI, Y.; BABOLI, A.; CHEIKHROUHOU, N.; MODARRES, M.; JOKAR, M. R. A. A rewarding-punishing coordination mechanism based on trust in a divergent supply chain. European Journal of Operational Research, v. 230, p. 527-538, 2013. crossref

ROCCATO, P. L. A Bíblia de canais de vendas e distribuição. São Paulo: M. Books, 2008.

SAMARA, B. S.; BARROS, J. C. Pesquisa de marketing: conceitos e metodologia. 3. ed. São Paulo: Pearson Prentice Hall, 2002.

SOARES, C. C. Introdução ao comércio exterior: fundamentos teóricos do comércio internacional. São Paulo: Saraiva, 2004. 
STANTON, W. J.; SPIRO, R. L. Administração de vendas. 10. ed. Rio de Janeiro: LTC, 2000.

VIEIRA, G. B. B. Regulamentação no comércio internacional: aspectos contratuais e implicações práticas. São Paulo: Aduaneiras, 2002.

Recebido: 18 jul. 2018

Aprovado: 14 fev. 2019

DOI: 10.3895/gi.v15n1.8571

Como citar:

ROSA, P. P.; VIEIRA, G. B. B.; FRANÇA JÚNIOR, R. S. As exportações por meio de agentes de venda pela ótica de empresas de médio porte localizadas em Caxias do Sul. R. Gest. Industr., Ponta Grossa, v. 15, n.

1, p. 134-164, jan./mar. 2019. Disponível em: <https://periodicos.utfpr.edu.br/rgi>. Acesso em: XXX

Correspondência:

Guilherme Bergmann Borges Vieira

Rua Francisco Getúlio Vargas, 1130, CEP 95070-560, Caxias do Sul, Rio Grande do Sul, Brasil

Direito autoral: Este artigo está licenciado sob os termos da Licença Creative Commons-Atribuição 4.0

Internacional.

(c) (1) 